\title{
SHIFT WORK AND METABOLIC SYNDROME, DIABETES MELLITUS AND ISCHAEMIC HEART DISEASE
}

\section{DOROTA SZOSLAND}

Nofer Institute of Occupational Medicine, Łódź, Poland

The National Centre for Workplace Health Promotion

\begin{abstract}
Shift work is affecting $20 \%$ to $25 \%$ employees and is becoming increasingly prevalent in contemporary life all over Europe and USA. It is associated with several health problems, such as e.g. metabolic syndrome, diabetes mellitus and cardiovascular disease. These diseases are possibly due to an impairment of biological rhythm. The metabolic syndrome is a complex of interrelated risk factors for cardiovascular disease and diabetes. Higher prevalence of the metabolic syndrome has been demonstrated among shift workers. Rotating shift work has an impact on each component of metabolic syndrome. Shift work might also have an impact on metabolic variables, and be a risk factor for type 2 diabetes. Only a few studies reported prevalence of impaired glucose metabolism and diabetes mellitus in relation to shift work. There is rather strong evidence in favour of association between shift work and coronary heart disease and that has been repeatedly demonstrated during over 20 years of research. Recent data increasingly reveal relations between shift work and plasma resistin, ghrelin, leptin and adiponectin.
\end{abstract}

Key words:

Shift work, Metabolic syndrome, Diabetes mellitus, Coronary heart disease

\section{INTRODUCTION}

Shift work is affecting $20 \%$ to $25 \%$ employees in manufacturing industries and is becoming increasingly prevalent in contemporary life all over Europe and USA. Continuous growth of shift worker numbers is observed also in the service sector [1]. The proportion of shift workers remains relatively constant up to 45 years of age but declines considerably among older workers [2].

\section{Shift work}

There is more than one definition of shift work. Council Directive 93/104/EC of 23 November 1993 concerning certain aspects of the organization of working time (as amended by Directive 2000/34 of 22 June 2000) defines shift work a "any method of organizing work in shifts whereby workers succeed each other at the same work stations according to a certain pattern, including a rotating pattern, and which may be continuous or discontinuous, entailing the need for workers to work at different times over a given period of days or weeks" $[3,4]$.

In general, the term "shift work" is quite vague and includes any organization of working hours that differ from the traditional diurnal work period; sometimes it is synonymous of irregular or odd working hours [5].

Another definition of shift work is given by Grosswald. Shift work refers to a job schedule in which employees work hours other than the standard hours of 8 a.m. to 5 p.m. or a schedule other than the standard workweek - Monday through Friday in the United States [6].

There is no precise definition of shift work. Most studies classify shift workers as anyone working outside regular daytime hours (i.e. between approximately 7 a.m. and 6 p.m., Monday through Friday). Under this definition, shift workers include all people working evening

Address reprint request to D. Szosland, Nofer Institute of Occupational Medicine, The National Centre for Workplace Health Promotion, św. Teresy 8, 91-348 Łódź, Poland (e-mail: szosland@imp.lodz.pl). 
shift, night shift, rotating shifts, split shifts or on-call schedules both during the week and on weekends [7]. There are thousands of shift systems that differ widely in their structure. Among shifts, alternating day shifts are most frequently used in Europe [8]. A major problem in numerous publications regarding shift work and health problems is the lack of one common definition of shift work.

Shift work is associated with several health problems, possibly due to an impairment of biological rhythm.

Over the last decades, Westernized countries have become 24-hour societies. That is why the interest concerning the influence of shift work on several health problems has been increasing all the time.

\section{Circadian rhythm}

Humans have natural body rhythms which are regulated by a "circadian clock" in the brain. These are called circadian rhythms. Circadian rhythm is an integrated body rhythm that cycles approximately every 24 hours.

Circadian rhythmicity can be important in the patophysiology of numerous diseases. In discussing health problems in shift workers, the role of circadian rhythm is the key issue. The circadian timing system proficiently coordinates the physiology of living to match it to the environmental or imposed 24-hour cycles. A wide range of biological processes are regulated by the circadian clock, including sleep-wake cycles, body temperature, energy metabolism, cell cycle and hormone secretion. Circadian regulation is important to maintain normal cellular functions. A disruption of core clock genes can be damaging to the organism's well-being [9-11]. Shift work is generally associated with chronic misalignment between the endogenous circadian timing system and the behavioural cycles, including sleep/wake and fasting/feeding cycles. There is a large amount of data pointing to an association between shift work and the prevalence of many medical conditions. Work/rest schedules resulting from shift work disrupt the circadian clock, causing symptoms similar to jet lag. Generally, no complete physiological (body function) adaptation takes place for the majority of night shift workers.

\section{Metabolic Syndrome}

The metabolic syndrome is a complex of interrelated risk factors for cardiovascular disease and diabetes. Several clinical definitions have been proposed.

The first criteria for definition for the diagnosis of metabolic syndrome were proposed by World Health Organization (WHO) in 1999 [12]. European Group for the Study of Insulin Resistance (EGIR) was in the same year the next one [13]. The presence of insulin resistance was a prerequisite in both definitions. National Cholesterol Education Program (NCEP) Adult Treatment Panel III in 2001 (ATP-III) does not obligatorily require impaired glucose regulation or insulin resistance as an essential component [14]. These three groups have agreed that the core components of the metabolic syndrome are: obesity, hypertension, insulin resistance and dyslipidemia. The levels set for each component and their combination required to diagnose the metabolic syndrome are slightly different in these three recommendations. In 2005 International Diabetes Federation (IDF) presented definition where visceral obesity was the necessary requirement. The American Heart Association and the National Heart, Lung and Blood Institute (AHA/NHLBI) modified the NCEP criteria by decreasing the glucose cut-off point [15]. All these definitions have been used by various authors. IDF and AHA/NHLBI representatives agreed that the abdominal obesity should not be a prerequisite for diagnosing of the metabolic syndrome. Abdominal obesity is one of the five criteria, while 3 of the 5 risk factors must be present to diagnose the syndrome [16]. Recently, common criteria for the clinical diagnosis of metabolic syndrome have been proposed by several major organizations in the Joint Scientific Statement in an attempt to unify all presented criteria [17]. Higher prevalence of the metabolic syndrome has been demonstrated among shift workers [18-21]. A recent study by De Bacquer et al. demonstrates that the risk of development of the metabolic syndrome gradually increases independently of the accumulated years of shift work. Rotating shift work has an impact on each component of metabolic syndrome [21]. Esquirol et al. show that shift work, regardless of models, was significantly associated with metabolic syndrome [22]. The risk of developing metabolic syndrome is high in night shift healthcare workers [23]. 


\section{Type 2 diabetes}

Type 2 diabetes is a modern world-wide epidemic. Its complications are a significant cause of morbidity and mortality in every European country and the consequences of its explosive growth are an intolerable burden both to the individual and to healthcare systems.

Diabetes type 2 is the most common form of diabetes and is characterized by disorders of insulin action and insulin secretion, either of which may be the predominant feature. Both are usually present at the time when this form of diabetes is clinically manifest [12]. The prevalence of diabetes continues to rise all over the world. The signs of abating are not observed [24].

There are rather few studies reporting prevalence of impaired glucose metabolism and diabetes mellitus in relation to shift work. Shift work might have an impact on metabolic variables, and also be a risk factor for type 2 diabetes. Suwazono et al. study on male Japanese workers revealed alternation/shift work was an independent risk factor for impaired glucose metabolism [25]. Kroenke et al. found a positive relation of hours worked with incidence of type 2 diabetes in a population of young and middle-aged women. The association was independent of body weight. The association between rotating night-shift work and diabetes was different. It was mediated by body weight, while job strain was unrelated to type 2 diabetes risk [26]. Mikuni et al. reported a higher prevalence of diabetes mellitus among shift workers [27]. Morikawa et al. study suggests that shift work is a risk factor for the onset of diabetes mellitus and that there are different risks associated with different types of shift schedule [28]. Diabetes risk increases with metabolic syndrome and varies substantially depending upon which factors are presented [29]. Knutson et al. study demonstrated the possibility of reduced sleep duration or quality could adversely affect glucose control in known diabetes [30].

\section{Cardiovascular disease}

The risk of cardiovascular disease among shift workers is well documented. Numerous publications on shift work and morbidity from cardiovascular disease confirm the relationship. That cardiovascular disease risk is increased among shift workers has been repeatedly demonstrated during over 20 years of research. There is rather strong evidence in favour of association between shift work and coronary heart disease [31-34].

Shift work can increase the risk of CVD by several mechanisms. Besides of psychological and psychosocial factors, physiological and biological mechanisms are crucial. They are usually related to activation of the autonomic nervous system, changed lipid, carbohydrate and other metabolic parameters. These factors may lead to increase risk for atherosclerosis, metabolic syndrome and type 2 diabetes. Coronary heart disease, metabolic syndrome and carbohydrate metabolism disturbances have some joint cause. Unphysiologic timing of physical activity in relation to circadian rhythms is a possible explanation for the negative impact on the cardiovascular system.

Recent data increasingly demonstrate relations between shift work and elevated plasma resistin levels. Resistin may play an important role in the pathogenesis of early metabolic syndrome components in young men chronically exposed to circadian misalignment [35]. Its circulating levels are predictive of coronary atherosclerosis [36]. Circulating adiponectin, ghrelin and leptin play an important role in human obesity, one of the components of metabolic syndrome, by the long term regulation of body weight and energy homeostasis [37]. Further studies in the shift work population are needed to sort out an important role of these in all elements of metabolic syndrome, diabetes and coronary health disease which are closely related to each other.

\section{REFERENCES}

1. Paoli P, Merllie D. Third European Survey on Working Conditions. European Foundation for the Improvement of Living and Working Conditions. Luxembourg: Office for Official Publications of the European Communities; 2001.

2. European Foundation for the Improvement of Living and working Conditions. European Quality of Life Survey 2003. Dublin 2003 [cited 2010 August 10]. Available from http:/www.eurofund.europa.eu/areas/qualityoflife/eqls/2003/ eqls.html. 
3. Council Directive 93/104/EC of 23 November 1993 concerning certain aspects of the organization of working time. Official Journal L 307, 13/12/1993.

4. Directive 2000/34/EC of the European Parliament and of the Council of 22 June 2000 amending Council Directive 93/104/ EC concerning certain aspects of the organization of working time to cover sectors and activities excluded from that Directive. Official Journal L 195, 01/08/2000.

5. Costa G. Factors influencing health of workers and tolerance to shift work. Theor Issues Ergon Sci 2003;4:263-88.

6. Grosswald B. The effects of shift work on family satisfaction. Families in Society. J Contemp Soc Serv 2004;85:413-23.

7. Institute for Work and Health. Fact sheet. Shiftwork. 2003 [cited 2010 August 15]. http://www.iwh.on.ca/media/images/ shiftwork.pdf.

8. Boisard P, Cartron D, Gollac M, Valleyre A. Temps et travail. Dublin: European Foundation for the Improvement of Living and Working Conditions; 2002.

9. Hastings MH, Reddy AB, Maywood ES. A clockwork web: circadian timing in brain and periphery, in health and disease. Nat Rev Neurosci 2003;4:649-61.

10. Morse D, Sassone-Corsi P. Time after time: inputs to and outputs from the mammalian circadian oscillators. Trends Neurosci 2002;25:632-7.

11. Rana S, Mahmood S. Circadian rhythm and its role in malignancy. J Circadian Rhythm 2010;8:3. DOI 10.1186/17403391-8-3.

12. WHO Department of Noncommunicable Disease Surveillance. Definition, Diagnosis and Classification of Diabetes Mellitus and its Complications Report of WHO Consultation. Geneva 1999 [cited 2010 August 10]. Available from http://www.staff.ncl.ac.uk/philip.home/who_dmg.pdf.

13. Balkau B, Charles MA. Comment on the provisional report from the WHO consultation. European Group for the Study of Insulin Resistance (EGIR). Diabet Med 1999;16:442-3.

14. Executive Summary of the Third Report of The National Cholesterol Education Program (NCEP) Expert Panel on Detection, Evaluation, and Treatment of High Blood Cholesterol In Adults (Adult Treatment Panel III). JAMA 2001;285: 2486-97.

15. Grundy SM, Cleeman JI, Daniels SR, Donato KA, Eckel RH, Franklin BA, et al. Diagnosis and management of metabolic syndrome: an American Heart Association / National Heart, Lung and Blood Institute Scientific Statement. Circulation 2005;112:2735-52.

16. Alberti KG, Zimmet P, Shaw J. Epidemiology Task Force Consensus Group. The metabolic syndrome: a new worldwide definition. Lancet 2005;365:1059-62.

17. Alberti KG, Eckel RH, Grundy SM, Zimmet PZ, Cleeman JL, Donato KA, et al. Harmonizing the Metabolic Syndrome. A Joint Interim Statement of the International Diabetes Federation Task Force on Epidemiology and Prevention; National Heart, Lung, and Blood Institute; American Heart Association; World Heart Federation; International Atherosclerosis Society; and International Association for the Study of Obesity. Circulation 2009;120:1640-5.

18. Karlson B, Knutsson A, Lindahl B. Is there an association between shift work and having a metabolic syndrome? Results from a population based study of 27,485 people. Occup Environ Med 2001;58:747-52.

19. Nagaya T, Yoshida H, Takahashi H, Kai M. Markers of insulin resistance in day and shift workers aged 30-59 years. Int Arch Occup Environ Health 2002;75:562-8.

20. Sookoian S, Gemma C, Fernandez GT, Burgueno A, Alvarez A, Gonzalez CD, et al. Effects of rotating shift work on biomarkers of metabolic syndrome and inflammation. J Intern Med 2007;261:285-92.

21. Esquirol J, Bongard V, Mabile L, Jonnier B, Soulat JM, Perret B. Shift work and metabolic syndrome: Impact of job strain, physical activity, and dietary rhythms. Chronobiol Int 2009;26:544-59.

22. De Bacquer D, Van Risseghem M, Clays E, Kittel F, De Backer G, Braeckman L. Rotating shift work and the metabolic syndrome: a prospective study. Int J Epidemiol 2009;38:848-54.

23. Pietroiusti A, Neri A, Somma G, Coppeta L, Iavicoli I, Bergamaschi A, et al. Incidence of metabolic syndrome among night-shift healthcare workers. Occup Environ Med 2010;67:54-7.

24. International Diabetes Federation. IDF Diabetes Atlas. 2010 [cited 2010 August 15]. Available from http://www. diabetesatlas.org/content/Europe.

25. Suwazono Y, Dochi M, Oishi M, Tanaka K, Kobayashi E, Sakata K. Shiftwork and impaired glucose metabolism: 
a 14-year cohort study on 7104 male workers. Chronobiol Int 2009;26:926-41.

26. Kroenke CH, Spiegelman D, Manson J, Schernhammer ES, Colditz GA, Kawachi I. Work Characteristics and Incidence of Type 2 Diabetes in Woman. Am J Epidemiol 2007;165: 175-83.

27. Mikuni E, Ohoshi T, Hayashi K, Miymura K. Glucose intolerance in an employed population. Tohoku J Exp Med 1983;141(Suppl):251-6.

28. Morikawa J, Nakagawa H, Miura K, Soyama Y, Ishizaki M, Kido T, et al. Shift work and the risk of diabetes mellitus among Japanese male factory workers. Scand J Work Environ Health 2005;31:179-82.

29. Nichols GA, Moler EJ. Diabetes incidence for all possible combinations of metabolic syndrome components. Diab Res Clin Pract. In press 2010. DOI 101016/j.diabres.2010.06.011.

30. Knutson KL, Ryden AM, Mander BA, Van Cauter E. Role of Sleep Duration and Quality in the Risk and Severity of Type 2 Diabetes Mellitus. Arch Intern Med 2006;166:1768-74.

31. Boggild H, Knutsson A. Shiftwork, risk factors and cardiovascular disease. Scand J Work Environ Health 1999;25:85-99.
32. Ha M, Park J. Shift work and metabolic risk factors of cardiovascular disease. J Occup Health 2005;47:89-95.

33. Thomas C, Power C. Shift work and risk factors for cardiovascular disease: a study at age 45 years in the 1958 British birth cohort. Eur J Epidemiol 2010;25:305-14.

34. Frost P, Kolstad HA, Bonde JP. Shift work and the risk of ischaemic heart disease - a systematic review of the epidemiologic evidence. Scand J Work Environ Health 2009;35: $163-79$

35. Burgueno A, Gemma C, Gianotti TF, Sookoian S, Pirola CJ. Increased levels of resistin in rotating shift workers: A potential mediator of cardiovascular risk associated with circadian misalignment. Atherosclerosis 2010;210:625-9.

36. Reilly MP, Lehrke M, Wolfe ML, Rohtagi A, Lazar MA, Radr DJ. Resistin in an inflammatory marker of atherosclerosis in humans. Circulation 2005;111:932-9.

37. Yildiz BO, Suchard MA, Wong ML, McCann S, Licinio J. Alterations in the dynamics of circulating ghrelin, adiponectin, and leptin in human obesity. PNAS 2004;101:10434-9. 